\title{
Intermediate and expanded FMR1 alleles in an autistic Costa Rican population
}

\author{
Rebeca Vindas-Smith ${ }^{1 *}$, Andrey Sequeira-Cordero ${ }^{1}$, Isabel Castro-Volio ${ }^{1 \dagger}$, Patricia Jiménez-González², \\ Patricia Cuenca ${ }^{1}$, Manuel Saborío-Rocafort'2, Marietha Fallas², and Melissa Vásquez ${ }^{1}$ \\ ${ }^{1}$ Instituto de Investigaciones en Salud, Universidad de Costa Rica; ${ }^{2}$ Hospital Nacional de Niños "Dr. Sáenz Herrera”, Caja Costarricense del Seguro \\ Social. San José, Costa Rica \\ tICV deceased on 29/09/2015.
}

\begin{abstract}
Objective: We aimed to determine the distribution of intermediate and expanded FMR1 alleles in Costa Rican individuals diagnosed with autism. Materials and methods: A total of 212 autism spectrum disorder (ASD) cases of Costa Rican individuals and 943 male newborn controls were screened by means of polymerase chain reaction to determine the frequency of intermediate, premutation, and full mutation FMR1 alleles. Full mutation suspected cases were confirmed by Southern blot analyses. Frequencies of FMR1 alleles in the case group were compared with frequencies observed in a population-based sample of male newborn controls. Results: A significant excess of intermediate allele carriers was found in ASD individuals as compared to controls ( $\chi^{2}$ test, $p<0.001$ ). Four, out of 188 males in the case group, were identified as full mutation carriers. Conclusions: Our results suggest a possible involvement of the gray zone or intermediate alleles in ASD.
\end{abstract}

Keywords: Autism spectrum disorder. Fragile X syndrome. Intermediate allele. Expanded allele. FMR1.

\section{Alelos intermedios y expandidos en el gen FMR1 en una población con autismo de Costa Rica}

\section{Resumen}

Objetivo: Determinar la distribución de los alelos FMR1 intermedios y expandidos en individuos costarricenses diagnosticados con autismo. Materiales y métodos: Para determinar la frecuencia de la mutación intermedia, la premutación y la mutación completa en el gen FMR1, se tamizaron 212 casos con autismo y 943 recién nacidos de sexo masculino como controles. Los casos con sospecha de ser portadores de la mutación completa se confirmaron mediante análisis de transferencia de Southern. Las frecuencias de los alelos del gen FMR1 en el grupo de casos se compararon con las frecuencias observadas en una muestra basada en la población de controles de recién nacidos varones. Resultados: Se encontró un exceso significativo de portadores de alelos intermedios en los individuos con autismo en comparación con los controles $\left(\chi^{2}, p<0.001\right)$. Cuatro varones del grupo de casos fueron identificados como portadores de la mutación completa. Conclusiones: Nuestros resultados sugieren una posible participación de los alelos intermedios en el autismo.

Palabras clave: Trastorno del espectro autista. Síndrome del cromosoma X frágil. Alelo intermedio. Alelo expandido. FMR1.

Correspondence:

${ }^{*}$ Rebeca Vindas-Smith

E-mail: rebeca.vindas@ucr.ac.cr
Date of reception: 17-05-2021

Date of acceptance: $30-10-2021$

DOI: 10.24875/RMN.21000044
Available online: 01-03-2022

Rev Mex Neuroci. 2022;23(2):51-56

www.revmexneurociencia.com 2604-6180 / @ 2021 Academia Mexicana de Neurología A.C. Published by Permanyer. This is an open access article under the CC BY-NC-ND license (http://creativecommons.org/licenses/by-nc-nd/4.0/). 


\section{Introduction}

Autism (OMIM 209850), also known as autism spectrum disorder (ASD), comprises a complex group of related behavioral disorders with a strong genetic component. ASD is characterized by impairments in social interactions, language, and communication skills, and by restricted and stereotypic behaviors and interests ${ }^{1}$. Based on its etiology, ASD may be classified as idiopathic, comprising $90-95 \%$ of cases; or as secondary, when the autistic phenotype is comorbid to another genetic/non-genetic condition².

The fragile $X$ syndrome (FXS) is a medical condition strongly associated with ASD. The clinical phenotype includes intellectual and emotional disabilities ranging from learning difficulties to intellectual disability, and mood instability ${ }^{1}$. In addition, around $30 \%$ of children diagnosed with FXS show autism-like neurobehavioral traits, including gaze avoidance, sensory hypersensitivity, social anxiety, stereotypies such as hand flapping and biting, and repetitive language ${ }^{1}$.

Mutations in the FMRP translational regulator 1 gene (FMR1, OMIM 309550) are responsible for the phenotypic consequences observed in FXS patients ${ }^{1}$. Most cases are due to expansions of the CGG-repeat number in the $5^{\prime}$-UTR within FMR1 exon $1^{3}$. Four allelic classes have been defined: (1) normal alleles, (2) intermediate or gray zone alleles, (3) premutation alleles, and (4) full mutation alleles. Normal alleles carry 6-44 CGG repeats. Intermediate or gray zone alleles overlap with normal and premutation alleles, which are normal but slightly unstable (i.e., alleles showing a slightly increased risk of expansion) and could lead to FXS in subsequent generations ${ }^{4}$. Despite that the American College of Medical Genetics (ACMG) has suggested a range of 45-54 CGGs for these alleles, it has not been accurately defined ${ }^{5-8}$. Premutation alleles carry 55-200 repeats with an increased risk of expansion to a full mutation through maternal transmission ${ }^{4}$. Premutation carriers show elevated FMR1 mRNA levels, which have been associated with the development of the fragile $\mathrm{X}$-associated tremor/ataxia syndrome (FXTAS) and fragile $X$-associated primary ovarian insufficiency ${ }^{4}$. Finally, individuals with the full mutation carry alleles longer than 200 CGG-repeats, which, in turn, are related to promoter hypermethylation leading to FMR1 silencing and FXS ${ }^{1}$. The absence of FMRP results in impaired synaptic function and neuroplasticity ${ }^{1}$.

Although the phenotypic effects of both intermediate and premutation alleles have received considerable attention, the involvement of intermediate alleles in clinical, behavioral, and cognitive phenotypes remains controversial. These alleles have shown a significantly higher frequency in subjects with parkinsonism ${ }^{9,10}$, ovarian dysfunction ${ }^{11,12}$, neurodevelopmental delay, and special educational needs ${ }^{13,14}$, even though some studies have failed to replicate similar results ${ }^{15,16}$. This study is aimed at determining the distribution of FMR1 alleles in Costa Rican individuals diagnosed with autism, and comparing the allele frequencies of intermediate and full mutation alleles observed in this group with frequencies established for a national birth cohort used as a control group.

\section{Materials and methods}

This study was a genetic screening focused on a population of ASD cases from the Central Valley of Costa Rica (CVCR). All cases of suspected autism were collected from this admixed population. A total of 212 participants with autism were recruited: 188 male and 24 female sporadic cases (i.e., only one affected child in each family). Subjects and parents were assessed using the Spanish version of the Autism Diagnostic Interview-Revised ${ }^{17}$ and the Autism Diagnostic Observation Schedule ${ }^{18}$. Inclusion criteria, descriptive and clinical data of the probands, ascertainment evaluation process, and clinical testing have been previously published $^{19,20}$. Parents of participating children provided written informed consent, whereas children also provided signed assent when possible. Blood samples were collected for DNA extraction and genetic FXS testing. The control group consisted of 943 males anonymously enrolled from the Costa Rican National Newborn Screening Program between May and October 2004.

\section{Molecular testing}

Genomic DNA was extracted from peripheral blood leukocytes using the proteinase K/phenol-chloroform approach ${ }^{21}$ and from Guthrie blood spots using the Chelex method $^{22}$. The number of CGG repeats was determined by polymerase chain reaction (PCR) according to $\mathrm{Fu}$ et al. ${ }^{3}$ with some minor modifications ${ }^{23}$ using the following primers: FRAXA-A (5'-GTCAGGCGTTCAGCTCCGTTT-3') and FRAXA-B (5'-CTCCATCTTCTCTTCAGCCCTGCT-3'). PCR was performed in a final volume of $25 \mu \mathrm{l}$ (100 ng of genomic DNA, $0.4 \mu \mathrm{M}$ of each primer, $200 \mu \mathrm{M}$ of each dNTP, 1X DNA polymerase buffer, $15 \%$ DMSO, $1.5 \mathrm{mM} \mathrm{MgCl}$, and $2 \mathrm{U}$ of GoTaq DNA polymerase [PROMEGA]). Reactions were carried out in a Perkin Elmer thermocycler GeneAmp PCR System 2400 with an initial denaturation step of $5 \mathrm{~min}$ at $95^{\circ} \mathrm{C}$, followed 
Table 1. Number of alleles and allele frequency distribution by geographic region in a sample of Costa Rican male newborns (controls)

\begin{tabular}{|l|c|c|c|c|c|c|}
\hline CGG-repeats & Central & Caribbean & North & Pacific & Chorotega & All regions \\
\hline $12-28$ & $133(23.7 \%)$ & $34(30.4 \%)$ & $16(19.1 \%)$ & $20(24.1 \%)$ & $24(23.1 \%)$ & $227(24.1 \%)$ \\
\hline 29 & $220(39.3 \%)$ & $38(33.9 \%)$ & $31(36.9 \%)$ & $30(36.1 \%)$ & $43(41.3 \%)$ & $362(38.4 \%)$ \\
\hline 30 & $173(30.9 \%)$ & $31(27.7 \%)$ & $30(35.7 \%)$ & $31(37.3 \%)$ & $28(26.9 \%)$ & $293(31.1 \%)$ \\
\hline $31-37$ & $34(6.1 \%)$ & $9(8.0 \%)$ & $7(8.3 \%)$ & $2(2.4 \%)$ & $9(8.7 \%)$ & $61(6.5 \%)$ \\
\hline Total & 560 & 112 & 84 & 83 & 104 & 943 \\
\hline
\end{tabular}

by 30 cycles of denaturation at $95^{\circ} \mathrm{C}$ for $30 \mathrm{~s}$, annealing at $59^{\circ} \mathrm{C}$ for $1 \mathrm{~min}$, and extension at $72^{\circ} \mathrm{C}$ for $1 \mathrm{~min}$, with a final 7 min extension step at $72^{\circ} \mathrm{C}$. The PCR products were analyzed on $8 \%$ polyacrylamide gels and stained with silver nitrate. When PCR was not informative, Southern blot hybridization was carried out. Finally, $5 \mu \mathrm{g}$ of genomic DNA was digested with Hind III (PROMEGA). The StB12.3 probe for DNA hybridization was used according to the procedure specified by Rousseau et al. ${ }^{24}$ with some modifications ${ }^{25}$.

\section{Statistical analyses}

Pearson's $\chi^{2}$ tests were used to compare allele frequencies in the sample of newborns between geographic regions of Costa Rica and to compare frequencies between ASD cases and controls. Data analyses were performed using SPSS software v19 (Chicago, IL). $\mathrm{P}<0.05$ was considered to be statistically significant.

\section{Results}

A total of $1179 \mathrm{X}$ chromosomes were screened for FMR1 CGG repeat number ascertainment, with 212 subjects fitting the diagnostic ASD criteria and 943 newborn males included as a control group. Thirty-two FMR1 alleles were identified in the entire Costa Rican sample (Supplementary Table 1). The normal allele distribution in the control group ranged from 12 to 37 , whereas in the case group ranged from 17 to 39 CGG repeats. All the individuals in the control group carried alleles from the normal range. The modal allele was 29 CGGs with a frequency of $37.3 \%(33.1 \%$ in cases and $38.3 \%$ in controls) and the second most common allele was 30 CGG-repeats with a frequency of $30.3 \%(27.1 \%$ in cases and $31 \%$ in controls) (Supplementary Table 1, Fig. 1).

Since the newborn control samples were collected from five geographic regions of Costa Rica (Table 1),
Table 2. FMR1 allele frequencies in 943 controls and 212 ASD cases ( $1179 \mathrm{X}$ chromosomes)

\begin{tabular}{|l|c|c|c|}
\hline Allelic form & CGG range & Controls & Cases \\
\hline Normal & $6-40$ & $943(100 \%)$ & $226(95.7 \%)$ \\
\hline Intermediate & $41-54$ & 0 & $6(2.5 \%)$ \\
\hline Pre-mutation & $55-200$ & 0 & 0 \\
\hline Full mutation & $>200$ & 0 & $4(1.7 \%)$ \\
\hline
\end{tabular}

the allele frequency distribution among these regions was also compared to identify possible geographic effects. However, no significant differences were found between regions $\left(\chi^{2}=10.41, \mathrm{gl}=12, \mathrm{p}=0.576\right)$.

In this study, alleles ranging from 41 to 54 CGG repeats were considered as intermediate or gray zone alleles. Six intermediate alleles $(2.5 \%)$ in the patient group were found (Table 2). Thus, a significant excess of intermediate alleles was observed in ASD individuals as compared to the control group $\left(\chi^{2}=24.51\right.$, $\mathrm{gl}=1, \mathrm{p}<0.001)$. Furthermore, given that all of the autistic cases were resident from the CVCR region, intermediate allele frequencies observed in this group were compared with frequencies in the control group from the same region. A significant difference between frequencies was found between cases and controls in the CVCR region $\left(\chi^{2}=14.59, \mathrm{gl}=1, \mathrm{p}=0.001\right)$.

Finally, no premutation carriers were detected either in the case or in the control group, whereas four full mutation carriers $(1.7 \%)$ were identified in the patient group (Table 2).

\section{Discussion}

This is the first study aimed to investigate FXS prevalence in Costa Rican children and adolescents diagnosed with ASD. The general Costa Rican population 


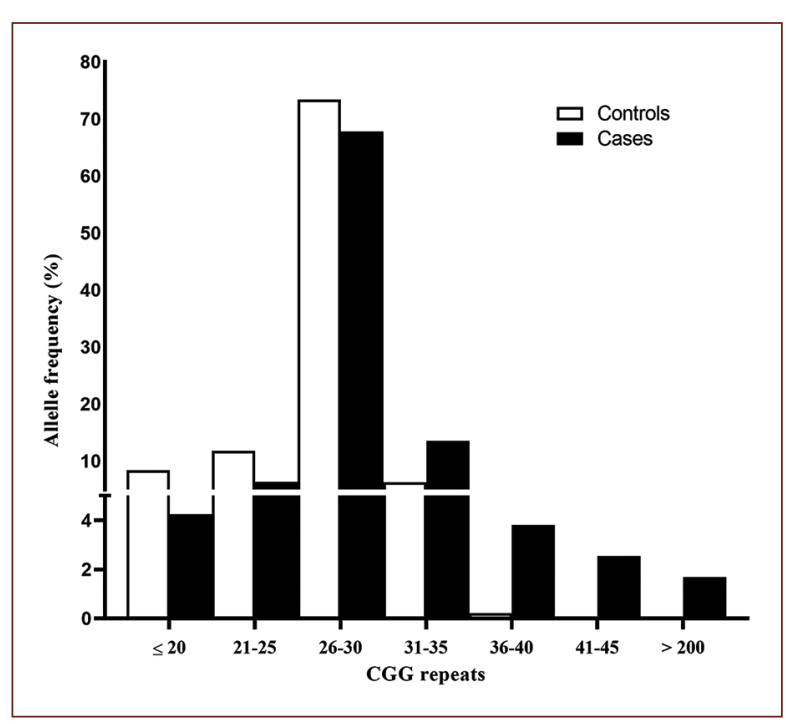

Figure 1. FMR1 CGG-repeat allele size distribution in 943 controls and 212 autism spectrum disorder cases.

as well as the CVCR current population arise from the admixture of ancestral Amerindian, European, and African groups ${ }^{26}$. As previously reported for populations with West European ancestry and for some Latin American countries, we found that alleles with 29 and 30 CGG-repeats were the more prevalent in the Costa Rican sample ${ }^{27,28}$. In fact, these alleles accounted for almost $68 \%$ of all screened $X$ chromosomes, with the 29 CGG repeat as the modal allele. Such a panorama is consistent with the European ancestral component as the main genetic component for Costa Rican population with a proportion of $49.2 \%$.

ASD is a neurodevelopmental disorder with an early onset during childhood and is associated with cognitive deficit and behavioral alterations such as a selective impairment in social interaction. Although no accurate tests for identifying the cause of ASD are available thus far, a genetic cause can be determined in some cases. It is widely known that FXS is the most common monogenic cause of autism, resulting in $2-6 \%$ of all cases ${ }^{2,29}$. Here, we found four full expanded alleles in a sample of 212 individuals ( $236 \mathrm{X}$ chromosomes), representing a frequency of $1.7 \%$. This variation could be explained by differential diagnostic criteria for participants' inclusion, differences in sample sizes, or population demographic history ${ }^{2}$. It has been reported that Native American populations have CGG-repeat alleles, and haplotypes related to the polymorphic loci characterized by considerable stability, suggesting a lower prevalence of FXS in these populations ${ }^{30}$. Taken altogether, these results support the notion that genetic analyses directed to determine
FMR1 repeats in ASD subjects are informative in a number of cases, favoring the accurate diagnosis and clinical management for a proportion of cases ${ }^{29,31}$. DNA testing from blood samples has not been a common practice for the FXS ascertainment in Costa Rican children with ASD, even though an accurate diagnosis is required for specific interventions with particular and appropriate clinical and developmental therapies. For this reason, the screening for FMR1 full mutation alleles is highly encouraged in individuals with idiopathic ASD in Costa Rica and other low- and middle-income countries. Accordingly, given the genetic basis of FXS, additional family members may also take advantage from carrier diagnosis and genetic counseling.

It is worth noting that several discrepancies regarding the definition of the intermediate or gray zone alleles can be found in the literature. Based on the assumption that below 45 CGG-repeats, no mitotic or meiotic instability occurs, the ACMG has established 45 CGGs as the lower and 54 CGG-repeats as the upper boundary? However, several studies have expanded the range by defining 34-41 CCG repeats as the lower and 60 CGGs as the gray zone upper bound ${ }^{5,8}$. We considered intermediate alleles as that ranging from 41 to 54 repeats based on molecular findings resulting in altered mRNA expression $^{32,33}$. Specifically, Loesch et al. ${ }^{33}$ showed a significant increase in FMR1 mRNA levels in intermediate allele carriers as compared to controls, and a positive relationship between these mRNA levels and CGG-repeat size in carriers within 41-54 repeats, evidencing transcriptional alterations in those individuals.

The frequency of the gray zone alleles was significantly higher in our ASD case group than in the control group, with $2.5 \%$ of the individuals carrying an intermediate allele in the case group as compared to $0 \%$ in the control group. Remarkably, similar results have been described for 42 Caucasian male children and adolescents $^{34}$ and for 96 Iranian boys with autism ${ }^{35}$, suggesting a putative involvement of intermediate alleles in cognitive/behavioral alterations related to autism. This suggestion should be taken cautiously since other studies have failed to replicate this association in cases with ASD or with special educational needs $s^{6,8,16,31}$. Nonetheless, it is worth noting that most of these studies $6,8,31$ found a non-significant trend toward a higher gray zone allele frequency in cases as compared to controls.

The distribution of intermediate alleles in the general population is quite frequent and ranges from 0.3 to $\sim 4 \%^{7}$ making difficult to draw a conclusion with regard to a relationship between these alleles and autism or other associated phenotypes. Since no robust evidence on 
intermediate alleles affecting behavioral and/or cognitive phenotypes has been described yet, these findings should be taken cautiously. Additional studies using larger cohorts in different populations with diverse genetic backgrounds should be considered. Furthermore, to establish a possible link between intermediate alleles and clinical outcomes, molecular and functional experiments are also needed.

In that regard, a toxic gain of RNA function has been proposed as a mechanism to explain the increased FMR1 mRNA levels in gray zone allele carriers, and the phenotypic effects documented in some of these individuals. Such mechanism resembles that one observed in pre-mutation carriers affected by FXTAS, where mRNA overexpression leads to intranuclear inclusions in brain cells, aggregation of rCGG-binding proteins involved in RNA processing and translational deficits of FMRP7,32,33. Loesch et al..$^{34}$ found a positive correlation between the expression levels of FMR1 and the DNA methyltransferase 1 (DNMT1) in intermediate allele carriers, suggesting an alteration of epigenetic mechanisms elicited by elevated FMR1 transcripts. In addition, elevated FMR1 mRNA levels in human cell lines containing premutation CGG-repeat expansions are associated to the upregulation of Ubiquitin Protein Ligase E3A (UBEA3) and Cytoplasmic FMR1 Interacting Protein (CYFIP), which are candidate genes associated with the development of $\mathrm{ASD}^{36}$. In a study with male carriers of intermediate and premutation alleles (40-85 CGG-repeats) affected by parkinsonism, it was found a positive correlation between clinical phenotype (motor and cognitive decline) and CGG-repeat size, antisense FMR1 transcript, and cytochrome $\mathrm{C} 1 \mathrm{mRNAs}$ levels (CYC1) in blood ${ }^{37}$. Subjects with Parkinsonism carrying intermediate/premutation alleles and with alterations in the CYC1 mRNA levels exhibited significant mtDNA depletion in blood compared with healthy controls and patients with Parkinsonism but with normal FMR1 alleles ${ }^{37}$. Although this was an unexpected result because CYC1 was initially used as a reference gene, the authors suggested a cytotoxic effect of elevated sense/antisense FMR1 messages that cause mitochondrial dysfunction and correlate with disease severity ${ }^{37}$. Impairments in mitochondrial function have a high prevalence in ASD subjects as compared to the general population ${ }^{38}$, and downregulation of $\mathrm{CYC1}$ in postmortem brain tissues from ASD patients has been reported ${ }^{39}$. As mentioned above, FMRP deficits have also been reported for subjects with elevated FMR1 mRNA levels, therefore, translational dysregulation of other relevant transcripts could also be involved.

Taken altogether, these observations suggest that, unlike the traditional view, intermediate alleles could result in phenotypic alterations potentially relevant for the ASD expression, at least in a minor percentage of patients. Recently, it has been described at the genome-wide level that tandem DNA repeat expansions contribute to the genetic risk of ASD in $2.6 \%{ }^{40}$. A top candidate of tandem repeat-containing regions was selected as ASD relevant in 10 genes including DM1 Protein Kinase, Frataxin, Calcium Voltage-Gated Channel Auxiliary Subunit Beta 1, and FMR1 among others ${ }^{40}$.

\section{Conclusions}

FMR1 screening in subjects with autism should be a common practice since a small fraction of individuals showing the autistic spectrum corresponds to non-diagnosed cases of FXS. We found a significantly increased of intermediate alleles frequency in a sample of Costa Rican children and adolescents diagnosed with ASD compared to a national newborn cohort, suggesting a possible role in the development of this condition. This category of alleles demands more epidemiological studies and a deeper biological comprehension to achieve a more appropriate genetic counseling.

\section{Acknowledgments}

We thank Fernando Ortiz and William Araya for technical assistance and Carolina Santamaría for manuscript reviewing. PJG and MF would like to thank Elina Manghi (University of Illinois, at Chicago) for her support regarding the development of genetic studies of autism in Costa Rica and who passed away on January 15, 2012. RVS, ASC, PC, and MV dedicate this work to the beloved memory of our collaborator ICV.

\section{Funding}

Funding for this study was provided by Consejo Nacional de Investigaciones Científicas y Tecnológicas (CONICIT) and Vicerrectoría de Investigación, Universidad de Costa Rica (742-A3-303).

\section{Conflicts of interest}

All authors declared that they have no conflicts of interest.

\section{Ethical disclosures}

Protection of human and animal subjects. The authors declare that the procedures followed were in 
accordance with the regulations of the relevant clinical research ethics committee (VI-4654-BIO-74-02) and with those of the Code of Ethics of the World Medical Association (Declaration of Helsinki).

Confidentiality of data. The authors declare that they have followed the protocols of their work center on the publication of patient data.

Right to privacy and informed consent. The authors have obtained the written informed consent of the patients or subjects mentioned in the article. PJG and MF are in possession of this document.

\section{Supplementary Data}

Supplementary data are available at Revista Mexicana de Neurociencia online at DOI: 10.24875/ RMN.21000044. These data are provided by the corresponding author and published online for the benefit of the reader. The contents of supplementary data are the sole responsibility of the authors.

\section{References}

1. Belmonte MK, Bourgeron T. Fragile $X$ syndrome and autism at the intersection of genetic and neural networks. Nat Neurosci. 2006;9:1221-25.

2. Reddy KS. Cytogenetic abnormalities and fragile $X$ syndrome in autism spectrum disorder. BMC Med Genet. 2005;6:3.

3. Fu YH, Kuhl DP, Pizzuti A, Pieretti M, Sutcliffe JS, Richards S, et al. Variation of the CGG repeat at the fragile $X$ site results in genetic instability: resolution of the Sherman paradox. Cell. 1991;67:1047-58.

4. Monaghan KG, Lyon E, Spector EB. ACMG standards and guidelines for fragile $X$ testing: a revision to the disease-specific supplements to the standards and guidelines for clinical genetics laboratories of the American college of medical genetics and genomics. Genet Med. 2013;1:575-86.

5. Bretherick KL, Fluker MR, Robinson WP. FMR1 repeat sizes in the gray zone and high end of the normal range are associated with premature ovarian failure. Hum Genet. 2005;117:376-82.

6. Crawford DC, Meadows KL, Newman JL, Taft LF, Pettay DL, Gold LB, et al. Prevalence and phenotype consequence of FRAXA and FRAXE alleles in a large ethnically diverse special education-needs population. Am J Hum Genet. 1999:64:495-507.

7. Hall DA. In the gray zone in the fragile $X$ gene: what are the key unanswered clinical and biological questions? Tremor Other Hyperkinet Mov. 2014;4:208-14

8. Mitchell RJ, Holden JJ, Zhang C, Curlis Y, Slater HR, Burgess T, et al. FMR1 alleles in Tasmania: a screening study of the special educational needs population. Clin Genet. 2005;27:113-7.

9. Kurz MW, Schlitter AM, Klenk Y, Mueller T, Larsen JP, Aarsland D, et al. FMR1 alleles in Parkinson's disease. J Geriatr Psychiatry Neurol. 2007;20:89-92

10. Loesch DZ, Tassone F, Lo J, Slater HR, Hills LV, Bui MQ, et al. New evidence for, and challenges in, linking small CGG repeat expansion FMR1 alleles with Parkinson's disease. Clin Genet. 2013;84:382-85.

11. Bodega B, Bione S, Dalprà L, Toniolo D, Ornaghi F, Vegetti W, et al. Influence of intermediate and uninterrupted FMR1 CGG expansions in premature ovarian failure manifestation. Hum Reprod. 2006;21:952-7.

12. Streuli I, Fraisse T, Ibecheole V, Moix I, Morris MA, de Ziegler D. Intermediate and premutation FMR1 alleles in women with occult primary ovarian insufficiency. Fertil Steril. 2009:92:464-70.

13. Murray A, Youings S, Dennis N, Latsky L, Linehan P, McKechnie N, et al. Population screening at the FRAXA and FRAXE loci: molecular analyses of boys with learning difficulties and their mothers. Hum Mol Genet. 1996;5:727-35

14. Youings SA, Murray A, Dennis N, Ennis S, Lewis C, McKechnie N, et al. FRAXA and FRAXE: the results of a five year survey. J Med Genet. 2000;37:415-21.

15. Kraff J, Tang HT, Cilia R, Canesi M, Pezzoli G, Goldwurm S, et al. Screen for excess FMR1 premutation alleles among males with parkinsonism. Arch Neurol. 2007;64:1002-6.
16. Madrigal I, Xunclà M, Tejada MI, Martínez F, Fernández-Carvajal I, Pérez-Jurado $L A$, et al. Intermediate FMR1 alleles and cognitive and/or behavioural phenotypes. Eur J Hum Genet. 2011;1:921-33.

17. Rutter M, LeCouteur A, Lord C. Autism Diagnostic Interview-revised (ADI-R). Los Angeles: Western Psychological Services; 2003.

18. Lord C, Rutter M, DiLavore PC, Risi S, Lambrecht L, Cook EH Jr., et al. Autism Diagnostic Observation Schedule (ADOS). Los Angeles: Western Psychological Services; 2001.

19. Manghi ER, Jiménez $P$, Esquivel M, Monge-Monge S, Fallas-Delgado $M$, Fournier $\mathrm{E}$, et al. Un estudio genético del autismo en Costa Rica: un modelo de trabajo para Latinoamérica. Psicol Iberoam. 2006;14:46-57.

20. Mclnnes LA, Jiménez-González $P$, Manghi ER, Esquivel M, Monge S, Delgado MF, et al. A genetic study of autism in Costa Rica: multiple variables affecting $I Q$ scores observed in a preliminary sample of autistic cases. BMC Psychiatry. 2005;5:15

21. Strauss WM. Preparation of genomic DNA from mammalian tissue. In: Ausubel FM, Brent R, Kinston RE, editor. Current Protocols in Molecular Biology. New York: Willey; 1998.

22. Polski JM, Kimzey S, Percival RW, Grosso LE. Rapid and effective processing of blood specimens for diagnostic PCR using filter paper and Chelex-100. Mol Pathol. 1998:51:215-7.

23. Cuenca P, Morales F, Castro I. Diagnóstico directo de la mutación que causa el síndrome del cromosoma X frágil. Experiencia en Costa Rica. Acta Méd Costarric. 2002; 44:27-33.

24. Rousseau F, Heitz D, Biancalana V, Blumenfeld S, Kretz C, Boué J, et al. Direct diagnosis by DNA analysis of the fragile $X$ syndrome of mental retardation. N Engl J Med. 1991;325:1673-81.

25. Vindas-Smith R, Cuenca-Berger P, Brenes-Pino F, Castro-Volio I. Tamizaje mediante inmunohistoquímica del síndrome del cromosoma $X$ frágil en una población de niños y adolescentes costarricenses. Act Méd Costarric. 2011;53:93-8.

26. Campos-Sánchez R, Raventos H, Barrantes R. Ancestry informative markers clarify the regional admixture variation in the Costa Rican population. Hum Biol. 2013;85:721-38.

27. Fernandez-Carvajal I, Walichiewicz P, Xiaosen X, Pan R, Hagerman PJ Tassone F. Screening for expanded alleles of the FMR1 gene in blood spots from Newborn males in a Spanish population. J Mol Diagn. 2009:11:324-9.

28. Milà M, Kruyer H, Glover G, Sánchez $A$, Carbonell $P$, Castellví-Bel $S$, et al. Molecular analysis of the (CGG)n expansion in the FMR-1 gene in 59 Spanish fragile X syndrome families. Hum Genet. 1994;94:395-400.

29. Dissanayake $C$, Bui $Q$, Bulhak-Paterson D, Huggins R, Loesch DZ. Behavioural and cognitive phenotypes in idiopathic autism versus autism associated with fragile $X$ syndrome. J Child Psychol Psychiatry. 2009:50:290-9.

30. Kunst CB, Zerylnick C, Karickhoff L, Eichler E, Bullard J, Chalifoux M, et al. FMR1 in global populations. Am J Hum Genet. 1996;58:513-22.

31. Tassone F, Choudhary NS, Tassone F, Durbin-Johnson B, Hansen R, Hertz-Picciotto I, et al. Identification of expanded alleles of the "FMR1" gene in the childhood autism risks from genes and environment (CHARGE) study. J Autism Dev Disord. 2013;43:530-9.

32. Kenneson $A$, Zhang $F$, Hagedorn $\mathrm{CH}$, Warren ST. Reduced FMRP and increased FMR1 transcrption is proportionally associated with CGG repeat number in intermediate-length and premutation carriers. Hum Mol Genet. 2001;10:1449-54.

33. Loesch DZ, Bui QM, Huggins RM, Mitchell RJ, Hagerman RJ, Tassone F. Transcript levels of intermediate size or grey zone fragile $X$ mental retardation 1 alleles are raised and correlate with the number of CGG repeats. J Med Genet. 2007;44:200-4

34. Loesch DZ, Godler DE, Khaniani M, Gould E, Gehling F, Dissanayake C et al. Linking the FMR1 alleles with small CGG expansions with neurodevelopmental disorders: Preliminary data suggest an involvement of epigenetic mechanisms. Am J Med Genet A. 2009;149:2306-10.

35. Shekari-Khaniani M, Amini-Yeganeh F, Amiri S, Mansouri Derakhshan S. Autistic phenotype of premutation and intermediate alleles of FMR1gene. Iran J Pediatr. 2017;27:e9445.

36. Handa V, Goldwater D, Stiles D, Cam M, Poy G, Kumari D, et al. Long CGG-repeat tracts are toxic to human cells: implications for carriers of Fragile X premutation alleles. FEBS Lett. 2005;579:2702-8.

37. Loesch DZ, Godler DE, Evans A, Bui QM, Gehling F, Kotschet KE, et al. Evidence for the toxicity of bidirectional transcripts and mitochondrial dysfunction in blood associated with small CGG expansions in the FMR1 gene in patients with parkinsonism. Genet Med. 2011; 13:392-9.

38. Rossignol DA, Frye RE. Mitochondrial dysfunction in autism spectrum disorders: a systematic review and meta-analysis. Mol Psychiatry. 2012;17:290-314.

39. Forés-Martos J, Catalá-López F, Sánchez-Valle J, Ibáñez K, Tejero H, Palma-Gudiel $\mathrm{H}$, et al. Transcriptomic metaanalyses of autistic brains reveals shared gene expression and biological pathway abnormalities with cancer. Mol Autism. 2019;10:17.

40. Trost B, Engchuan W, Nguyen CM, Thiruvahindrapuram B, Dolzhenko E, Backstrom I, et al. Genome-wide detection of DNA tandem repeats that are expanded in autism. Nature. 2020;586:80-6. 